\title{
Successful management of Mirizzi’s Syndrome, an uncommon complication of gallstone disease
}

\author{
Ezekiel Wong Toh Yoon ${ }^{1 *}$, Kazuki Nishihara ${ }^{1}$ and Sunao Otagaki ${ }^{2}$ \\ ${ }^{1}$ Department of Internal Medicine (Gastroenterology), Hiroshima Kyoritsu Hospital, Hiroshima City, Japan \\ ${ }^{2}$ Department of Surgery, Hiroshima Kyoritsu Hospital, Hiroshima City, Japan
}

\section{Key clinical message}

Mirizzi's Syndrome is a rare complication of gallstone disease. Preoperative diagnosis and management can pose a challenge. Cholangiography is the gold standard for diagnosis and minimally invasive laparoscopic cholecystectomy can be employed as mainstay treatment depending on the type of diagnosis.

\section{Introduction}

Gallstone disease is one of the most common digestive diseases. Mirizzi's Syndrome is a rare complication of gallstone disease and was originally described by Pablo Louis Mirizzi as an obstructive jaundice caused by a stone impacted at the neck of the gallbladder or at the cystic duct [1]. The reported incidence varies from $0.05-2.7 \%$ in patients with cholelithiasis and $0.7-1.4 \%$ of patients undergoing cholecystectomy [2]. The clinical presentation of patients is nonspecific, ranging from no symptoms to severe cholangitis. Therefore, accurate diagnosis and management can pose a challenge even to seasoned clinicians [3].

We herein report the successful management of a 54-year-old man with Mirizzi’s Syndrome in our hospital.

\section{Case report}

A 54-year-old man was admitted into our hospital for severe right upper quadrant and epigastric pain. Other than a slight fever $\left(37.3^{\circ} \mathrm{C}\right)$ and mild tachycardia ( 98 beats per minute, regular), his vital signs were stable. Abdominal examination demonstrated a positive Murphy's sign with slight involuntary guarding. Laboratory findings on admission revealed leukocytosis $(9,720 / \mu \mathrm{L})$ and a high C-reactive protein level $(17.69 \mathrm{mg} / \mathrm{dL})$, strongly suggesting the presence of inflammation. Liver and biliary enzymes were elevated, with total bilirubin at $4.5 \mathrm{mg} / \mathrm{dL}$, AST 128 U/L, ALT 189 U/L, LDH 252 U/L, ALP 471 U/L and $\gamma$-GTP $438 \mathrm{U} / \mathrm{L}$.

Abdominal CT scan confirmed an enlarged gallbladder with wall edema and an impacted gallstone (about $10 \mathrm{~mm}$ in diameter) in the cystic duct. Magnetic resonance cholangiography (MRC) was performed on day 2 and revealed compression of the common hepatic duct as well as the proximal portion of the common bile duct by the inflamed gallbladder (Figure 1, arrow). No stones were detected in the common bile duct.

He was treated conservatively with intravenous hydration and antibiotics but because elevation of liver and biliary enzymes as well as inflammatory markers persisted, we conducted an endoscopic retrograde cholangiography (ERC) on day 6. Endoscopic imaging during
ERC revealed a normal ampulla of Vater (Figure 2). Cholangiography confirmed stenosis of the common hepatic duct and proximal portion of the common bile duct due to compression by the gallbladder (Figure 3 , arrow). There were no gallstones in the common bile duct and no fistulas (cholecystobiliary or bilio-enteric) were detected.

A diagnosis of Type 1 Mirizzi's Syndrome was established and the patient was transferred to the surgical ward on day 7 . He underwent laparoscopic cholecystectomy on day 8 and oral intake was resumed from day 10. He experienced no postoperative complications and was discharged on day 16 (postoperative day 7) after marked improvements in laboratory findings.

\section{Discussion}

Because the gallbladder is connected at its neck to the cystic duct which empties into the common bile duct, gallstones impacted in the cystic duct or in Hartmann's pouch can cause obstruction of the common hepatic duct or common bile duct through either direct mechanical compression (impacted stone or inflamed gallbladder) or

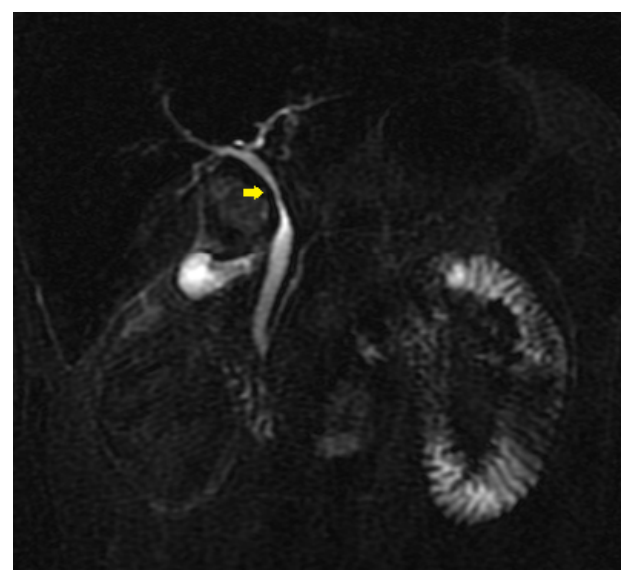

Figure 1. Magnetic resonance cholangiography (MRC) revealing a compressed common hepatic duct and common bile duct.

Correspondence to: Dr. Ezekiel Wong Toh Yoon, Department of Internal Medicine, Hiroshima Kyoritsu Hospital, 2-20-20 Nakasu Asaminami-ku Hiroshima City, Japan; Tel: 8182-879-1111; E-mail: easybs@hotmail.com

Key words: Mirizzi's Syndrome, Gallstone disease, Laparoscopic cholecystectomy

Received: August 12, 2016; Accepted: August 24, 2016; Published: August 31, 2016 


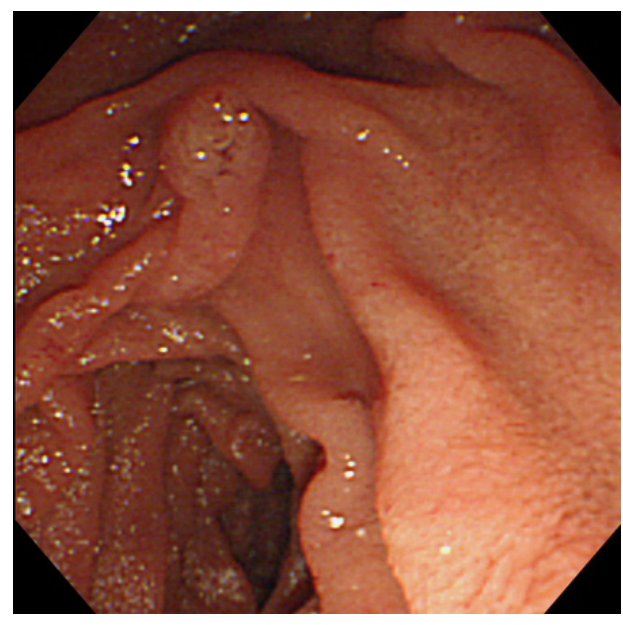

Figure 2. Endoscopic imaging during endoscopic retrograde cholangiography (ERC) revealing a normal ampulla of Vater.

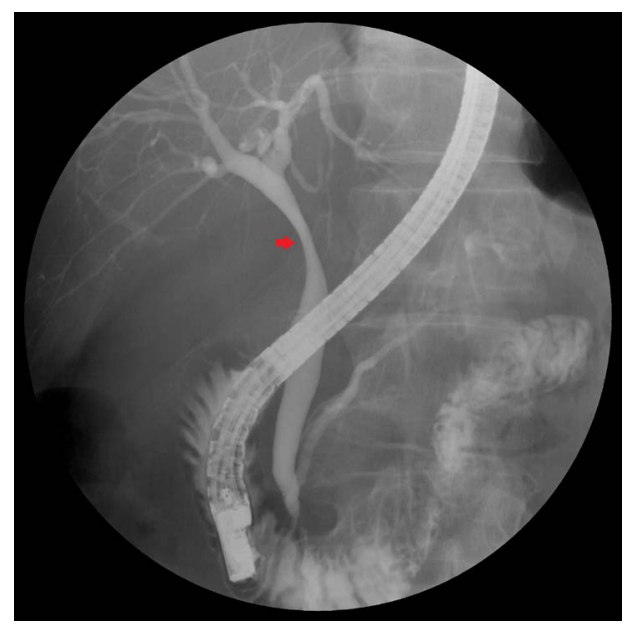

Figure 3. Endoscopic retrograde cholangiography (ERC) confirming stenosis of the common hepatic duct and common bile duct due to compression by the gallbladder.

secondary inflammation. The resulting jaundice and elevation in liver as well as biliary enzymes is typical of Mirizzi's Syndrome [1-3].

Mirizzi's Syndrome can be classified into 4 types which is defined by 4 evolving stages according to the presence and extent of a fistula in the common bile duct [4]. Type I, only external compression without fistula, is the most common and simplest type [5]. Cholangiography remains the most reliable method for the diagnosis of this syndrome, with ERC being the gold standard. Although, like in our patient's case, MRC may also be of diagnostic value, it lacks the option of therapeutic intervention in case of complications such as choledocholithiasis and may not be as sensitive in diagnosing the presence of fistulas (Types II to IV).

The mainstay of therapy for Mirizzi's Syndrome is surgery to remove the causal factors. Although technically challenging, minimally invasive laparoscopic cholecystectomy has been shown to be a safe and effective method [6]. Endoscopic treatment can be considered as a temporizing measure before surgery but this approach is not always feasible and should be reserved for unsuitable surgical candidates [7]. As for the timing of laparoscopic cholecystectomy, some studies have shown that early laparoscopic cholecystectomy (performed within 7 days of symptom onset/admission) in acute cholecystitis may reduce major bile duct injury and lower hospital cost [8-9]. Nevertheless, major bile duct injury incidence was much less than $1 \%$ regardless of the timing and recent studies have also demonstrated that laparoscopic cholecystectomy performed after the so called " 72 hours safe period" or after diagnosis is safe as well as more practical [10-12].

\section{Conclusion}

In conclusion, Mirizzi's Syndrome, as part of the differential diagnosis for obstructive jaundice in acute cholecystitis, can be diagnosed preoperatively and management with minimally invasive laparoscopic approach in the common Type 1 seems to be safe and effective.

\section{References}

1. Mirizzi PL (1948) Syndrome del conducto hepatico. J Int de Chir. 8: 731-777.

2. Kumar A, Senthil G, Prakash A, Behari A, Singh RK, et al. (2016) Mirizzi's syndrome: lessons learnt from 169 patients at a single center. Korean J Hepatobiliary Pancreat Surg 20: 17-22. [Crossref]

3. Elhanafy E, Atef E, El Nakeeb A, Hamdy E, Elhemaly M, Sultan AM (2014) Mirizzi Syndrome: How it could be a challenge. Hepatogastroenterology. 61: 1182-1186. [Crossref]

4. Csendes A, Díaz JC, Burdiles P, Maluenda F, Nava O (1989) Mirizzi syndrome and cholecystobiliary fistula: a unifying classification. Br J Surg 76: 1139-1143. [Crossref]

5. Al-Akeely MH, Alam MK, Bismar HA, Khalid K, Al-Teimi I, et al. (2005) Mirizzi syndrome: ten years experience from a teaching hospital in Riyadh. World J Surg 29 1687-1692. [Crossref]

6. Kamalesh NP, Prakash K, Pramil K, George TD, Sylesh A, et al. (2015) Laparoscopic approach is safe and effective in the management of Mirizzi syndrome. J Minim Access Surg 11: 246-250. [Crossref]

7. England RE, Martin DF (1997) Endoscopic management of Mirizzi's syndrome. Gut 40: 272-276. [Crossref]

8. de Mestral C, Rotstein OD, Laupacis A, Hoch JS, Zagorski B, et al. (2014) Comparative operative outcomes of early and delayed cholecystectomy for acute cholecystitis: a population-based propensity score analysis. Ann Surg. 259: 10-15. [Crossref]

9. Wu XD, Tian X, Liu MM, Wu L, Zhao S, Zhao L (2015) Meta-analysis comparing early versus delayed laparoscopic cholecystectomy for acute cholecystitis. Br J Surg. 102: 1302-1313. [Crossref]

10. Farooq T, Buchanan G, Manda V, Kennedy R, Ockrim J (2009) Is early laparoscopic cholecystectomy safe after the "safe period"? J Laparoendosc Adv Surg Tech A 19: 471-474. [Crossref]

11. Gurusamy KS, Davidson C, Gluud C, Davidson BR (2013) Early versus delayed laparoscopic cholecystectomy for people with acute cholecystitis. Cochrane Database Syst Rev. (6):CD005440. [Crossref]

12. Roulin D, Saadi A, Di Mare L, Demartines N, Halkic N (2016) Early Versus Delayed Cholecystectomy for Acute Cholecystitis, Are the 72 hours Still the Rule?: A Randomized Trial. Ann Surg. [Crossref]

Copyright: (C2016 Toh Yoon EW. This is an open-access article distributed under the terms of the Creative Commons Attribution License, which permits unrestricted use, distribution, and reproduction in any medium, provided the original author and source are credited. 